Bentham OPEN

\title{
Lifestyle Factors that can Induce an Independent and Persistent Low- Grade Systemic Inflammatory Response: A Wholistic Approach
}

\author{
George Vrousgos ${ }^{*}$ \\ School of Health and Human Sciences, Southern Cross University, Lismore, NSW, Australia
}

Received: February 20, 2015

Revised: May 13, 2015

Accepted: May 20, 2015

\begin{abstract}
Subclinical inflammation was first shown in numerous chronic medical illnesses and in the early 1900s, activation of immune-inflammatory pathways was initially observed in a lifestyle-related disorder such as depression. A chronic mild inflammatory state is also a key feature of obesity as well as insulin resistance and other metabolic diseases. This particular form of immune process has given rise to the concept of "metaflammation" (metabolically triggered inflammation) because it can target vital organs and tissues that are critical for the regulation of metabolism, and ultimately disrupt systemic homoeostasis with detrimental health effects. However, accumulating evidence demonstrates a link between metaflammation and a number of lifestyle factors. Lifestyle variables such as ultra-endurance exercise, physical inactivity, extremes of sleep duration, cigarette smoking, burnout, anxiety, and depression can activate multiple immune-inflammatory pathways. Therefore, this review of the literature that bears hallmarks of a systematic review investigates and presents published research data of these lifestyle factors that can induce an independent and persistent low-grade systemic inflammatory response, within the human body, evaluated through the measurement of various biomarkers.
\end{abstract}

Keywords: Anxiety, Burnout, Cigarette Smoking, Depression, Extremes of Sleep Duration, Metaflammation, Physical Inactivity, Ultra-Endurance Exercise.

\section{INTRODUCTION}

Subclinical inflammation was first shown in numerous chronic illnesses, including cardiovascular disease (CVD), multiple sclerosis, rheumatoid arthritis, systemic lupus erythematosus, and diabetes [1 - 14]. However, in the early 1900 s, disturbances in acute phase plasma proteins were initially detected in a lifestyle-related disorder such as depression [15]. In addition, persistent activation of immune-inflammatory pathways is associated with an increased risk of a wide spectrum of medical conditions such as CVD, atherosclerosis, metabolic syndrome, arthritis, type 2 diabetes, certain cancers, and functional decline [1 - 14]. A chronic mild inflammatory state is also a key element of obesity as well as insulin resistance and other metabolic diseases [16]. This particular form of immune process has given rise to the concept of "metaflammation" (metabolically triggered inflammation) because it can target vital organs and tissues that are critical for the regulation of metabolism, and ultimately disrupt systemic homoeostasis [17].

Classical inflammation is defined as the protective, short-term immune response of the body tissues to irritation or injury that eventually results in healing and a return to normal homoeostasis. Its cardinal signs include redness, heat, swelling, and pain, usually accompanied by loss of function [18]. Compared to classical inflammation, metaflammation increases the inflammatory markers only to a slight degree with ensuing chronic, rather than acute, allostasis; exerts its effects systemically rather than topically; its antigens are less apparent as unknown agents; it is linked with a decreased, rather than an elevated, rate of metabolism [19]; and, finally, it does not resolve a disease but most of its characteristics tend to perpetuate disease $[17$ - 20].

There is a direct connection between increasing obesity and the incidence of obesity-related comorbidities including

\footnotetext{
* Address correspondence to this author at the Department of Health and Human Services, State Government of Victoria, Australia; Tel: +61+423063174; Email: George.Vrousgos@dhhs.vic.gov.au
} 
diabetes and hypertension with raised levels of inflammatory biomarkers. These biomarkers comprise, but are not limited to, serum concentrations of C-reactive protein (CRP), fibrinogen [21], interleukin-6 (IL-6), and tumor necrosis factor-alpha (TNF-a) [22]. Interleukin-4 (IL-4) and interleukin-10 (IL-10) are also classified as anti-inflammatory cytokines since they can lower the production of proinflammatory cytokines such as TNF-a and IL-6 [23]. The antiinflammatory properties of adiponectin, a protein hormone, have also been proposed [24, 25]. Plasma adiponectin levels have been inversely related to insulin resistance [26, 27]. Adiponectin is chiefly synthesized in subcutaneous fat cells and it is released primarily by adipocytes (fat cells), while inflammatory cytokines are secreted mostly from non fat cells in adipose (fatty) tissue [28].

Growing evidence demonstrates a link between metaflammation and a number of lifestyle factors. Health practitioners from different disciplines need to be aware of the negative environmental, psychological and lifestyle influences in order to collaborate with each other and advise their clients appropriately to diminish and avoid the detrimental effects on health, of this form of inflammation [29]. Lifestyle variables such as ultra-endurance exercise, physical inactivity, extremes of sleep duration, cigarette smoking, burnout, anxiety, and depression can activate multiple immune-inflammatory pathways. The primary aim of this literature review that bears hallmarks of a systematic review is to explore and present published research data of these lifestyle factors that can induce an independent and persistent low-grade systemic inflammatory response, within the human body, evaluated through the measurement of various biomarkers.

\section{LITERATURE SEARCH METHOD}

For the purpose of this review of the literature, the identification of research articles was conducted with the aid of the EBSCOhost online research database service provided through Southern Cross University of Australia. Electronic databases including the AMED, MEDLINE, CINAHL Plus with Full Text, PsycARTICLES, PsycINFO, and SPORTDiscus with Full Text, were systematically searched for relevant articles. Multiple searches were performed using Boolean operators with the following combinations of research terms, depending on the focus area of the topic:

- Low-Grade Systemic Inflammation: Low-grade/low grade systemic inflammation, low-grade/low grade inflammatory response/reaction, metaflammation, C-reactive protein, cytokine(s).

- Ultra-Endurance Exercise: Ultra-endurance exercise, ultraendurance exercise, ultra endurance exercise, ultramarathon, ultramarathon, ultra marathon, triathlon.

- Physical Inactivity: Physical inactivity, physical activity, sedentary lifestyle.

- Extremes of Sleep Duration: Sleep quality, sleep duration, sleep loss, sleep deprivation, insomnia, not obstructive, not apnea/apnoea.

- Cigarette Smoking: Cigarette smoking, smoking, cigarette smoke, adiponectin.

- Burnout: Burnout, vital exhaustion.

- Anxiety: Anxiety, anxious.

- Depression: Depression, depressive, depressed.

The above keywords were thoroughly scrutinized within the abstracts of the articles. Hand-searching was also performed using the reference lists of the retrieved articles for the identification of additional pertinent studies. Only clinical trials reported in English language that recruited non obese and apparently healthy individuals, or if there was convincing adjustment for these confounding factors, met the inclusion criteria for this review.

The literature search yielded thirty four original research studies and all of them were included in this review. These articles can be grouped according to the focus of the search topic. Four clinical trials covered ultra endurance exercise [30 - 33] while three were used for physical inactivity [34 - 36]. For sleep, six studies were collated [29, 37 - 41] while five reported on cigarette smoking [42 - 46]. One article concentrated on burnout [47], one on anxiety [48], and thirteen emerged for depression [49 - 61]. Finally, one clinical study was found to be useful because it enclosed all three lifestyle factors such as burnout, anxiety, and depression [62]. 


\section{RESULTS}

\section{Ultra Endurance Exercise}

Ultra endurance exercise is defined as any prolonged exercise that lasts for more than six hours ( $>6 \mathrm{~h}$ ) in duration [63]. During normal exercise, cytokines (e.g., IL-6) may be produced and discharged by contracting skeletal muscle fibres, exerting anti-inflammatory actions in other body organs and areas against diseases associated with low-grade inflammation such as cardiovascular disease, some cancers and type 2 diabetes [64, 65]. TNF-a synthesis is also suppressed by exercise offering protection against TNF-a-induced insulin resistance [65]. Yet, an ultra endurance exercise can create a stronger anti-inflammatory cytokine reaction. For instance, this type of reaction happened within half an hour after a triathlon race where the cytokines interleukin IL-1, IL-6 and IL-10, heat shock protein 70 (HSP70) as well as IL-12p40 (the p40 subunit of interleukin-12), and granulocyte colony-stimulating factor (G-CSF) were markedly heightened. The day after the race, however, only IL-1, IL-6, and plasma G-CSF concentration remained significantly augmented [33].

In another clinical trial [31] with longer duration, similar results were reported. More specifically, the prominent immediate initial systemic inflammatory response, with increases in total leukocyte counts, myeloperoxidase (MPO), polymorphonuclear (PMN) elastase, cortisol, creatine kinase (CK) activity, myoglobin, IL-6, IL-10 and CRP, that was provoked by an Ironman triathlon declined very quickly. Nevertheless, a low-grade systemic inflammatory response, with elevated CK activity, myoglobin, IL-6 and CRP, persisted up to at least five days after the end of this type of exercise, probably indicating incomplete muscle recovery. As a result of this attenuated immune reaction, individuals may be more liable to infections within this first period of recuperation. Additionally, inadequate rest following extended, intensive exercise without a satisfactory recovery period could particularly incite a chronic systemic inflammatory state, causing a syndrome of impaired performance and progressive fatigue. For this reason, it would be highly advisable to actively recover by exercising at a low-intensity level, for at least two to three weeks, prior to gradually returning to a more demanding training program.

Furthermore, changes in clinical markers of inflammation after ultra endurance exercise can differ depending on the form and duration of exercise [33]. For example, this was demonstrated by Gomez-Merino and colleagues [30] when they compared the systemic cytokine responses after two endurance races of similar duration but with differences in muscle strain; a long distance triathlon (consisting of sequential swimming, cycling and running) and a 100-km run. At the end of both races, greater rises in plasma values of interleukin IL-6, IL-1 ra (interleukin-1 receptor antagonist), and IL-10 were noticed in the triathletes compared to the runners, while levels of the chemokine IL- 8 enhanced only in the runners. Moreover, the positive associations that were observed between IL-6 and free fatty acid (FFA) concentrations in the triathletes, and between IL-8, CK and HSP72 in the runners, designated that IL-6 release is rather related to energy substrate availability during protracted exercise while IL-8 release is linked with a high degree of mechanical restraint on the lower limbs and vascular inflammation. Consequently, triathletes were less predisposed to muscular damage due to the fewer eccentric (muscle lengthening) contractions, while runners appeared the most prone to muscle damage in consideration of increased values of the muscle-specific enzyme, creative kinase, loss of muscular flexibility and physical performance decline.

Nieman and colleagues [32], in a comparative study among non steroidal anti-inflammatory (NSAID) users and nonusers, did not reveal any differences in CK or level of muscle soreness. However, the study unexpectedly showed two to three times greater rise in five of seven cytokines in the NSAID (primarily ibuprofen) users. More precisely, muscle damage, on account of elevated CK activity in athletes taking part in a 160-km race, was notably correlated with post-race muscle soreness and increases in IL-6, G-CSF, IL-10, IL1 ra, and MCP-1 (monocyte chemotactic protein-1), but not IL-8 and MIP-1b (macrophage inflammatory protein-1b).

\section{Limitations/Implications for Further Research}

A number of limitations and implications for further research have been recognized. Future research could specify whether NSAID use augments cytokine reactions following ultramarathons through an endotoxaemia pathway. Secondly, in view of the fact that there is no beneficial effect of NSAIDS in alleviating muscle soreness and damage after contraction-induced muscle injury [32], a question that is raised is whether there are any safe and effective nutritional, classical homoeopathic, or herbal substances that can be used before, during or after ultraendurance exercise to lessen this type of inflammatory response aiding healing and enhancing physical performance. In addition, subsequent investigations would clarify whether, after ultra endurance exercise, anti-inflammatory cytokines are 
generated chiefly in response to muscle damage or other factors [33]. Moreover, all of the above clinical trials included a small sample size [30 - 33] with a maximum of sixty athletes in only one of them [32]. Also, additional studies of long follow up are needed. Lastly, new clinical trials recruiting equal number of male and female participants are necessary since three studies involved only male participants [30, 31, 33], and only one engaged both sexes [32].

\section{Physical Inactivity}

In healthy individuals, even short-term physical inactivity associated with bed rest was interrelated to the development of insulin resistance, dyslipidaemia, and increased blood pressure as well as impaired microvascular function. Nonetheless, the above changes took place without an elevation in systemic inflammatory markers (CRP, IL-6, or soluble TNF receptor 2) or a reduction in serum adiponectin levels [35]. In contrast, Hamer and Chida [34] found that physical inactivity was associated with heightened concentrations of CRP. Additionally, this association appeared to be extensively correlated, in a linear manner, with several other inflammatory biomarker values. For instance, after adjusting a number of confounding factors, lower levels of physical activity, compared with the highest quintile of physical activity, were coupled with augmented concentrations of CRP, fibrinogen, and soluble intracellular adhesion molecule 1 (ICAM-1) that can encourage the initiation and progression of atherosclerosis and cardiovascular disease [36].

The underlying molecular mechanisms leading from sedentary lifestyle to cardiovascular events in humans are incompletely understood [66]. However, invasive tests on vascular function in mice exhibited that physical inactivity can stimulate vascular nicotinamide adenine dinucleotide phosphate (NADP) oxidase expression and activity, boosting vascular reactive oxygen species (ROS) production. As a consequence, sedentary lifestyle as opposed to a more physically active way of life can result in endothelial dysfunction, and ultimately accelerate the formation of atherosclerotic lesions [67].

\section{Limitations/Implications for Further Research}

Firstly, the cross-sectional design that was applied was not ample enough to identify the directionality or causal nature of the associations between inflammatory markers and physical inactivity. For example, inflammatory markers could be both a cause and a consequence of physical inactivity restricting the prognostic impact of the findings. Other weaknesses with implications for further research include the fact that blood samples were collected and measured at one point in time only [34,36]; in the analysis of one study there was no adjustment for sleep, alcohol intake, diet, and psychological factors [36]; the small sample size of twenty subjects [35]; the researchers recruited only women into their sample [36]; the short duration of bed rest - only five days; there was no randomization for the subjects to normal activity or bed rest; the assessment of vascular function was non-invasive by simply measuring reactive hyperaemia. Therefore, these limitations could have influenced the results. As a final point, more human studies are required to illustrate the exact mechanisms that are responsible for the rapid development of vascular dysfunction and insulin resistance during physical inactivity [35].

\section{Extremes of Sleep Duration}

Extremes of sleep duration, greater than eight hours $(>8 \mathrm{~h})$ or less than six hours $(<6 \mathrm{~h})$, can also negatively affect health through the activation of pro-inflammatory pathways [29]. Polysomnography (PSG) is a non-invasive, comprehensive electronic monitoring of the biophysiological changes that occur during sleep and wakefulness, which involves the attachment of multiple sensors to the person's body [68]. Elevations in self-reported habitual sleep duration $(>8 \mathrm{~h})$ were coupled with increases in CRP and IL-6, whereas reduced PSG sleep length ( $<6 \mathrm{~h})$ was linked with raised TNF-a level. Furthermore, these rises or decreases of the level of the inflammatory markers appeared to take place in a linear fashion [29]. Yet, in the morning after a night of partial sleep deprivation (staying awake from $11 \mathrm{pm}$ to $3 \mathrm{am}$ ), both the concentrations of IL-6 and TNF-a were strikingly higher proportionate to morning levels following uninterrupted sleep (from $11 \mathrm{pm}$ to $7 \mathrm{am}$ ). In addition, the magnitude of the production of these inflammatory markers was similar between the two sexes [37]. Likewise, mononuclear cell nuclear factor-kappaB (NF-kB) (a protein complex) activation was remarkably increased in comparison with morning concentrations after continuous sleep (11 pm to $7 \mathrm{am}$ ). This response implied that NF-kB activation is a molecular pathway by which sleep loss may well have an effect on leukocyte inflammatory gene expression as well as the likelihood of inflammation-related disease. It is of great interest to state that this NF-kappaB activation was seen in female partakers and not in male partakers [38]. 
Conversely, in a clinical trial [40] that included only young women, poor sleep quality and continuity were associated with augmented CRP laboratory values, but not with IL-6 or TNF-a, while no relation was established between sleep duration and any of the inflammatory biomarkers. Similar observations were obtained by a large population based study [41] where no important relationship was found between CRP levels and sleep duration (polysomnographic or self-reported). Also, it is evident that increasing age, the male gender, and African American ethnicity compared with Caucasian American ethnicity, tended to have poorer sleep [39]. Despite that, independent of demographic factors, endothelin-1 (ET-1), a potent vasoconstrictor and mediator of inflammation elicited from endothelial cells [69], was correlated with more deep sleep, while both ET-1 and IL-6 were associated with larger latency of sleep and with rapid eye movement (REM) [39]. Accordingly, it is imperative to sustain an ideal range, between seven and eight hours of uninterrupted sleep per night, in order to elude the unhealthy effects of the associated inflammatory processes [70].

\section{Limitations/Implications for Further Research}

Both sleep measures (self-reported and polysomnographic) have their limits in the proper evaluation of sleep duration [29, 41]. During the recruitment process, for instance, subjects that met the inclusion criteria in the clinical studies were those that regularly slept between 10:30 pm and 7:30 am [37,38]. This assessment was conducted by the use of a sleep diary for two weeks. Nonetheless, the application of actigraphy would have provided a more precise evaluation of sleep duration [37, 38, 40]. Actigraphy is a non-invasive technique of monitoring human rest/activity cycles which uses a small instrument called an actigraph that is worn on the wrist or ankle [71]. Hence, sleep length may have overestimated true sleep exposure due to the reliance on self-reported habitual sleep time. On the other hand, PSG sleep time may not correspond to the usual nightly exposure because of the first-night effect of sleeping in an unknown setting $[29,41]$.

However, the validity of the results was greater enhanced given that the cytokine production was repeatedly assessed at baseline as well as immediately after the end of the intervention [37, 38] whereas in two studies [39, 40] only one blood sample was obtained, and this occurred at the convenience of the subjects (between 10 am and 4 pm) [40]. Having such inconsistency in collection times, besides the fact that cytokines concentrations are lowest during the day [72], may to some extent explain why no correlation was found between sleep quality and IL-6 or TNF-a and levels may have been too low to be detected [40]. Undoubtedly, a more appropriate design, principally for IL-6, which displays a circadian rhythm, should incorporate numerous sampling times [39]. Moreover, Okun and colleagues [40] enrolled only female subjects in their trial. In addition, the fact that no clinical evaluation was carried out did not provide data such as BMI (body mass index), presence of sleep disorders, current infections, or medications used; all of which are factors that can influence the inflammatory markers [73].

Investigators are also required to confirm the consequences of sleep deprivation on inflammatory mechanisms with ramifications for cardiovascular and chronic inflammatory disorders, in humans. Testing of interventions that would endorse sleep and/or its biological consequences could define new strategies to hinder inflammatory responses, and thus promoting health. Further clinical studies that use signal antagonists will need to verify the possible mechanisms involved in the production of inflammatory cytokines [37]. Similarly, trials entailing repeated measures of NF-kB would have to appraise the temporal dynamics of activation of this transcription factor across the diurnal period and with respect to sleep disturbance. The fact that the effect of sleep loss on activation of the transcription factor NF-kB primarily happens in females but not in males, necessitates careful interpretation taking into account the small sample size and their exploratory nature. Yet, if these results on sex differences are supported by other studies as well, it would offer inferences for understanding the differential risk profile for inflammatory disorders between the two sexes [38]. Additional research is also of great importance to substantiate whether increasing age, the male gender, and African American ethnicity compared with Caucasian American ethnicity, are related to poorer sleep [39]; and, if this is the case, why?

\section{Cigarette Smoking}

In a non-diabetic and non-obese population, smoking was linked in a different way with subclinical inflammatory processes between the two sexes, with reduced adiponectin concentrations in women and with elevated CRP levels in men [42]. The raised values of CRP in males who smoke, in comparison to non-smokers, is in agreement with former findings by García-Lorda and colleagues [43]. Other investigators have reported a positive relationship between smoking status and high CRP level, and especially among heavier past-month smokers as opposed to light and moderate 
smoking. In adolescents, in whom the lifetime cumulative cigarette use exposure is a lot less compared to adult smokers, cigarette smoking increased CRP concentrations soon after smoking commenced. Consequently, damage related to cigarette smoking may begin soon after tobacco use. This reinforces the preventive message that no level of smoking is safe in youth [45]. Also, particular attention should be paid to public health policies that emphasize smoking cessation [42].

Further, the observation that women who smoke have diminished adiponectin values [42] is consonant with a prior published study [46] where smoking was allied with decreased concentrations of adiponectin in both genders. In contrast to this and some earlier results $[42,44,46]$, there was no report of any connection between smoking and adiponectin values in the male participants. The lower level of adiponectin in women who smoke may be attributable to differences in fat distribution, with men having relatively more visceral and less subcutaneous fat than women [74]. In addition, a noteworthy fall in the adiponectin values was observed only twelve hours after smoking in those that have never smoked previously [44]. Moreover, the adiponectin level tended to lessen according to the increase in the number of cigarettes smoked [44, 46]. Considering the function of adiponectin in controlling insulin sensitivity and vascular protection, the finding that current smoking was dose-dependently associated with diminished adiponectin concentrations, could partially provide a rationale for why smokers are insulin resistant and at higher risk of cardiovascular disease [46].

However, soon after smoking cessation, the CRP level started declining and the adiponectin value started elevating in a linear fashion [46]. Interestingly, this relation between CRP and smoking can persist for a minimum of ten years [75] or even up to thirty years or more [76]. Furthermore, the linkage between adiponectin and smoking can also remain for a minimum of ten years [46] suggesting that some smoking effects may continue for lengthy periods of time [44, 76]. Therefore, it is critical that more emphasis is placed not only in smoking cessation but also in the prevention of initiating cigarette smoking [46].

\section{Limitations/Implications for Further Research}

The deleterious health consequences of cigarette smoking have been well described. Smoking enhances the risk of serious diseases as well as the mortality from cardiovascular diseases and cancer [77]. Long-term smoking can lead to insulin resistance [78] but the underlying mechanisms remain to be fully elucidated [46]. Additionally, adiponectin level is interrelated independently with the vasodilator response to reactive hyperaemia, and its concentration may well be an autonomous parameter of endothelial function [25]. Also, endothelial dysfunction, an early marker of atherosclerosis, has been noted in chronic smokers and following acute cigarette smoking [79, 80]. These effects suggest that adiponectin could be a mediator between smoking and conditions such as hypertension and coronary artery disease (CAD) [44].

Cigarette smoking and tissue hypoxia have been coupled with stimulation of the TNF-a system [81 - 83] or other proinflammatory status [84]. TNF-a can inversely regulate adiponectin secretion by inhibition of the adiponectin promoter activity [44, 85]. Further, nicotine, a major component of cigarette smoke, can augment the synthesis of TNFa via functional nicotinic acetylcholine receptor in rat adipocytes [86]. As a result, TNF-a axis activation stimulated by smoking may partly justify the present observations. Other potential mechanisms by which smoking habit could have an impact on adiponectin level are the increased oxidative stress [87] via inhibition of the secretion and expression of adiponectin in adipocytes [44], an anti-oestrogenic action [88] or sympathetic nerve activation [89]. Yet, tobacco smoke consists of more than 4,000 chemical components, and constituents such as cadmium, cotinine, and thiocyanate may also be toxic to adipocytes [90]. For this reason, it is unattainable to foresee the net effect of nicotine and oxidative stress within this complex mixture of elements [44]. Moreover, smoking could most likely have an effect on compounds, other than the adipocytes, of visceral adipose tissue and boost the release of IL- 6 resulting in elevated CRP production in hepatic cells [91]. However, forthcoming exploration ought to corroborate this.

There are other limitations and implications for further research that should be addressed. Even though the researchers adjusted for the degree of obesity as determined by body mass index (BMI), the results may, to a certain degree, be explained by the difference in fat distribution, something that BMI cannot alone accurately reflect [44, 46]. As a consequence, more clinical studies are needed to measure waist circumference or computed tomography (CT)obtained visceral fat mass [46]. Additional examination would guarantee whether fat distribution can explicate the diverse effects of smoking on pro-inflammation and adiponectin associated with gender [42]. Furthermore, although the cross-sectional design precludes conjecture concerning causality [44 - 46], the subjects were probably not aware of their CRP values, and therefore, it is highly unlikely that CRP concentrations could have an influence upon cigarette use 
[45]. Also, Iwashima and colleagues [44] included only male subjects in their study and the sample of Takefuji and colleagues [46] was restricted to Japanese people. The lack of determination of sex hormones [42] can also be a confounding factor. In addition, smoking intensity could have been reported inaccurately or underreported in the selfadministered questionnaire. Upcoming clinical trials, consisting of other populations with more promising measures of smoking, are vital in order to validate and extend our understanding of the exact mechanisms by which smoking may affect adiponectin levels. Further, new studies are needed focusing on the chronological alteration in adiponectin values with respect to the change in smoking status [46]. Finally, future investigation is required to assess the effect of passive smoking on adiponectin [44] and CRP concentrations.

\section{Burnout}

Burnout is defined as a chronic affective condition characterized by emotional exhaustion, physical fatigue, along with cognitive weariness [92, 93]. There is a known relationship between burnout and cardiovascular disease risk. Burnout, in women and not in men, was positively connected with higher levels of CRP and fibrinogen values [62]. In contrast to Toker and colleagues [62] where burnout was differentially related to micro-inflammation biomarkers, dependent on gender, von Känel and colleagues [47] did not find such a difference. To be more specific, burnout syndrome was associated with increased TNF-a concentrations, decreased IL-4 levels, and an enhanced TNF-a/IL-4 ratio. As a result, burnout was linked not only with augmented proinflammatory activity but also with lower antiinflammatory action. This systemic response was predominantly noticed when burnout was conceptualised as a unidimensional construct and along a continuum of symptom severity rather than categorically. Accordingly, the fact that burnout is correlated with microinflammation may have undesirable implications for the cardiovascular system.

\section{Limitations/Implications for Further Research}

First, the findings were based on cross-sectional data, and hence, the temporal ordering of the relation between burnout with CRP and fibrinogen levels cannot be definitively ascertained [62]. Also, the cross-sectional design of the study did not allow for cytokine measures to mirror the dynamics of the cytokine network, where, for instance, antiinflammatory cytokines heighten in response to an elevation in proinflammatory cytokines [47]. Further research concentrating on prospective studies would determine the causality and the mechanisms responsible for this connection in an attempt to decipher the specific physiological processes involved [47, 62]. For more conclusive observations, additional studies are warranted to investigate whether these results are replicated.

Second, the findings point to the need to inquire into the likelihood of gender differences. Third, it would be interesting to explore the probable interactive effect of burnout and other positive as well as negative affective states on inflammatory and conventional CVD risk factors. Fourth, upcoming research could examine the impending influence of personality features, like neuroticism, on the association between burnout and inflammation. Fifth, the possible various linkages among the elements of the burnout syndrome and CVD endpoints and risk factors could also be searched [62]. Lastly, future studies would particularly profit from conceptualising burnout as a continuous measure rather than as a categorical dimension [47].

\section{Anxiety}

Anxiety, a complex feeling of uneasiness, fear and worry [94], has been coupled with increased risk of coronary heart disease (CHD) [95].This emotional state was also associated with inflammation and coagulation markers in cardiovascular disease-free people signifying another pathophysiological link that amplifies the risk of cardiovascular incidents in anxious individuals. Precisely, anxiety in men was found to be positively interconnected with C-reactive protein, tumor necrosis factor-alpha, interleukin-6, homocysteine, as well as fibrinogen concentrations; and, in women, positively linked with CRP, white blood cell counts, interleukin-6, homocysteine, and fibrinogen levels [48]. Similar observations of anxiety being positively related to higher values of CRP and fibrinogen concentrations were also taken by Toker and colleagues [62]. Yet, this correlation was witnessed only in men.

\section{Limitations/Implications for Further Research}

The previously mentioned results were based on cross-sectional data [48, 62], and consequently, the temporal ordering of the connection between anxiety with CRP and fibrinogen cannot be definitively discerned [62]. These findings, however, propose a new pathophysiological relationship between anxiety and markers of inflammation associated with cardiovascular disease. Nonetheless, the underlying mechanisms have not been fully rationalized and 
further research is required to shed light on existing knowledge and pave the way for more effective interventions. In addition, although there was adjustment for a number of potential confounding variables, nothing was stated regarding adjustment of sleep [48].

\section{Depression}

Stewart and colleagues [57], during a long prospective cohort study, assessed the longitudinal relations between depressive symptoms as evaluated by the Beck Depression Inventory-Second Edition (BDI-II), with both IL-6 and CRP. According to these researchers, depression was coupled with larger six-year increases in serum IL-6. Even though a weak bidirectional association between BDI-II and CRP was also detected, the observations were most consistent with the notion that depressive symptoms may lead to, rather than result from, augmented inflammatory processes and that inflammation may be one of the mechanisms through which depression enhances the pathogenesis of cardiovascular disease. Also accordant with these results, Matthews and colleagues [56] did not deduce a relationship between baseline depressive symptoms and alterations in CPR over a five-year follow up.

Paralleling the findings of Stewart and colleagues [57], Boyle and colleagues [49] showed that a composite score representing the linear combination between depression, hostility, and anger scales predicted ten-year elevations in the third complement protein $(\mathrm{C} 3)$, which is an additional CAD-related inflammatory marker. Further, the observation by Gimeno and colleagues [53] that the cognitive symptoms of depression were not connected to twelve-year changes in IL-6 and CPR is aligned with the BDI-II subscale analyses of Stewart and colleagues [57], where it was observed that the somatic-vegetative subscale, and not the cognitive-affective one, preceded and predicted subsequent rises in serum IL-6.

Several other clinical trials $[50,52,58,59,61]$ have inferred that there is a significant linkage between depression and inflammatory markers such as CRP, IL-6, and intercellular adhesion molecule-1 (ICAM-1). Nevertheless, the majority of them have concluded that inflammation accounts for only a small percentage of the cardiotoxic effect and the incidence of CHD of depression, indicating that multiple mechanisms are involved. On the contrary, only one study [55] reported that a depressive mood state interacted synergistically with CRP to predict future CHD events, as such, individuals with both depression and increased CRP were at considerably higher risk. Also, two clinical studies recommended that this correlation between a heightened level of depressive symptoms with elevated CRP [51, 62] and fibrinogen [62] concentrations was only evident in men. These results connote that depressive mood could have different psychological and physiological interconnections between the two sexes [51]. Negative findings have also been stated. As an example, Hung and colleagues [54] revealed no association between inflammatory biomarkers such as CRP, TNF-a and IL-6, and different types of depression.

Overall, the existing clinical trials adduce proof that the relationship between depression and inflammation is bidirectional and complicated. Even though the observations point out that the depression-to-inflammation connection might be stronger than the inflammation-to-depression relation, the degree of either direction of this link may depend on the depressive symptom clusters studied, the inflammatory markers evaluated, and the populations examined [57]. In the elderly, for instance, inflammation, as measured by raised baseline CRP value, notably predicted accelerated development of depressive symptoms [60]. Consequently, the current results evince that anti-inflammatory approaches may also be an effective avenue to reduce the inimical effects of depression on cardiovascular health [57].

\section{Limitations/Implications for Further Research}

First, the cross-sectional study design is not able to affirm the temporal order between depression with CRP and fibrinogen [51, 62]. More prospective data are required to prove the directionality of the depression-inflammation association [57, 62]. Yet, treatment with the cytokine interferon-a and peripheral administration of IL-6 intensify depressive symptoms [96, 97]. Moreover, anti-inflammatory medications such as cyclooxygenase-2 inhibitors [98] and tumor-necrosis factor antagonists [99] have been shown to lessen the severity of depressive symptoms. However, new randomized controlled trials of medication exclusively influencing either depressive symptoms or CRP would provide fundamental information about the interconnection between CRP and depression. This relationship between depression and CRP would further be clarified by longitudinal studies using other measures of inflammation as well as clinical trials in individuals with genetically augmented CRP level [51].

Second, only a single measurement of depressive symptoms and each inflammatory marker, at baseline [50, 58] and at the end of the follow-up period, was obtained [57]. Due to the fact that depressive symptoms [100] and markers of inflammation [101 - 103] may vary within the same person, the baseline and follow-up values would have been more 
trustworthy if the researchers had measured and averaged two separate readings, at both time points [14]. Furthermore, by assessing depression at one time point only, it did not allow for transient states of depression to be differentiated from persistent ones [55]. Future studies with multiple measurements during follow-up would disclose the most biologically plausible processes by which these risk factors interact with each other [50].

Third, potential confounders, at baseline or during follow up, that were not considered in the clinical trials included the deficient information on antidepressants' use or the use of any other psychiatric medication [50, 51], nonprescription medication use [50,56] or acute inflammatory diseases [51 - 56], which can also affect the biomarkers. Additionally, the increased CRP concentration was a stronger predictor of the somatic subscale compared to the affective symptoms of the BDI-21 (21-item version of Beck's Depression Inventory) denoting that fatigue could also be a confounding factor of the correlation between depression and CRP levels. Thus, fatigue may need to be viewed as a confounding factor in further studies [51].

Fourth, the evaluation of depression was performed by the use of a symptom rating scale which is not considered a very thorough assessment method [55]. However, a reconsideration of its validity and reliability was auspicious [104]. Finally, the findings could be biased due to the low sample size [54] as well as due to the fact that the sample of the trials $[49,52,54-57,59]$ was restricted to female [56, 59], male [49, 52, 54, 55], white [52, 57], or hospitalized subjects. Hence, the results of the individual studies cannot be extrapolated to both genders, other ethnic backgrounds, and different settings [54].

\section{CONCLUSION}

All related published research data on lifestyle factors that can conduce to an independent and persistent low-grade systemic inflammatory reaction and activation of immune-inflammatory pathways within the human body, has been presented. More specifically, the variables that were investigated in this review included ultra-endurance exercise, physical inactivity, extremes of sleep duration, cigarette smoking, burnout, anxiety, and depression. Upcoming research should concentrate on additional prospective clinical trials that would determine the causality and the mechanisms involved in the association between lifestyle implications and metaflammation. For more conclusive findings, further human studies on healthy individuals with large samples, engaging both sexes from a variety of ethnic backgrounds, preferably randomized (if feasible) to minimise bias, of long follow-up, are essential. Also, repeated measurements of inflammatory biomarkers just before the intervention, during the intervention (where applicable), and after the end of the intervention, would produce more concrete evidence. Future clinical trials need to test for specific lifestyle influences and with very strict control or adjustment for all confounding factors that can have an impact on the biomarkers of inflammation so that the results are more accurate and convincing.

Although all of these aspects of lifestyle that can activate a variety of immune-inflammatory pathways should be avoided, it would be beneficial and interesting to know, with further research studies, which combinations of factors are more damaging to health and which ones are less harmful. However, the focus of the interventions should not be so much at achieving an anti-inflammatory effect at a biochemical level but in fact identifying and resolving the true causes behind the development of such lifestyle behaviours. Maintaining a fine balance, by having a non stressful, physically active, happy and meaningful way of life, with adequate sleep duration and quality, as well as sufficient rest, that avoids ultra-endurance exercise and cigarette smoking, would definitely minimize and prevent the unfavourable health risks of metaflammation. Therefore, it is crucial that health practitioners from different disciplines are aware of all the negative environmental, psychological and lifestyle dynamics in order to gain greater insight into working together and advising their clients appropriately, thus promoting optimal health and averting disease in a wholistic manner.

\section{CONFLICT OF INTEREST}

The author confirms that this article content has no conflict of interest.

\section{ACKNOWLEDGEMENTS}

The author would like to thank the following people: Dr. Sonya Brownie for encouraging him to publish this literature review; the anonymous reviewers for their constructive comments; Dr. Matthew Piscioneri for the proofreading; and, finally, Dr. Sandra Grace for the letter of recommendation to the editor. 


\section{REFERENCES}

[1] Ferrucci L, Harris TB, Guralnik JM, et al. Serum IL-6 level and the development of disability in older persons. J Am Geriatr Soc 1999; 47(6): $639-46$

[http://dx.doi.org/10.1111/j.1532-5415.1999.tb01583.x] [PMID: 10366160]

[2] Ford ES. Body mass index, diabetes, and C-reactive protein among U.S. adults. Diabetes Care 1999; $22(12): 1971-7$. [http://dx.doi.org/10.2337/diacare.22.12.1971] [PMID: 10587828]

[3] Haverkate F, Thompson SG, Pyke SD, Gallimore JR, Pepys MB. Production of C-reactive protein and risk of coronary events in stable and unstable angina. Lancet 1997; 349(9050): 462-6. [http://dx.doi.org/10.1016/S0140-6736(96)07591-5] [PMID: 9040576]

[4] Kilic T, Ural D, Ural E, et al. Relation between proinflammatory to anti-inflammatory cytokine ratios and long-term prognosis in patients with non-ST elevation acute coronary syndrome. Heart 2006; 92(8): 1041-6. [http://dx.doi.org/10.1136/hrt.2005.080382] [PMID: 16547209]

[5] Paoletti R, Bolego C, Poli A, Cignarella A. Metabolic syndrome, inflammation and atherosclerosis. Vasc Health Risk Manag 2006; 2(2): 145-52.

[PMID: 17319458]

[6] Pearson TA, Mensah GA, Alexander RW, et al. Markers of inflammation and cardiovascular disease: application to clinical and public health practice: A statement for healthcare professionals from the Centers for Disease Control and Prevention and the American Heart Association. Circulation 2003; 107(3): 499-511.

[http://dx.doi.org/10.1161/01.CIR.0000052939.59093.45] [PMID: 12551878]

[7] Pradhan AD, Manson JE, Rifai N, Buring JE, Ridker PM. C-reactive protein, interleukin 6, and risk of developing type 2 diabetes mellitus. JAMA 2001; 286(3): 327-34.

[http://dx.doi.org/10.1001/jama.286.3.327] [PMID: 11466099]

[8] Ridker PM, Rifai N, Pfeffer M, Sacks F, Lepage S, Braunwald E. Elevation of tumor necrosis factor-alpha and increased risk of recurrent coronary events after myocardial infarction. Circulation 2000; 101(18): 2149-53.

[http://dx.doi.org/10.1161/01.CIR.101.18.2149] [PMID: 10801754]

[9] Ridker PM, Cushman M, Stampfer MJ, Tracy RP, Hennekens CH. Inflammation, aspirin, and the risk of cardiovascular disease in apparently healthy men. N Engl J Med 1997; 336(14): 973-9.

[http://dx.doi.org/10.1056/NEJM199704033361401] [PMID: 9077376]

[10] Ridker PM, Rifai N, Stampfer MJ, Hennekens CH. Plasma concentration of interleukin-6 and the risk of future myocardial infarction among apparently healthy men. Circulation 2000; 101(15): 1767-72.

[http://dx.doi.org/10.1161/01.CIR.101.15.1767] [PMID: 10769275]

[11] Sakkinen P, Abbott RD, Curb JD, Rodriguez BL, Yano K, Tracy RP. C-reactive protein and myocardial infarction. J Clin Epidemiol 2002; 55(5): 445-51. [http://dx.doi.org/10.1016/S0895-4356(01)00502-9] [PMID: 12007546]

[12] Tziakas DN, Chalikias GK, Kaski JC, et al. Inflammatory and anti-inflammatory variable clusters and risk prediction in acute coronary syndrome patients: a factor analysis approach. Atherosclerosis 2007; 193(1): 196-203.

[http://dx.doi.org/10.1016/j.atherosclerosis.2006.06.016] [PMID: 16857204]

[13] Volpato S, Guralnik JM, Ferrucci L, et al. Cardiovascular disease, interleukin-6, and risk of mortality in older women: the women's health and aging study. Circulation 2001; 103(7): 947-53. [http://dx.doi.org/10.1161/01.CIR.103.7.947] [PMID: 11181468]

[14] Willerson JT, Ridker PM. Inflammation as a cardiovascular risk factor. Circulation 2004; 109 (21 Suppl 1): II2-10. [http://dx.doi.org/10.1161/01.CIR.0000129535.04194.38] [PMID: 15173056]

[15] Maes M, Scharpe S, Bosmans E, et al. Disturbances in acute phase plasma proteins during melancholia: additional evidence for the presence of an inflammatory process during that illness. Prog Neuropsychopharmacol Biol Psychiatry 1992; 16(4): 501-15. [http://dx.doi.org/10.1016/0278-5846(92)90056-K] [PMID: 1379370]

[16] Wellen KE, Hotamisligil GS. Inflammation, stress, and diabetes. J Clin Invest 2005; 115(5): 1111-9. [http://dx.doi.org/10.1172/JCI200525102] [PMID: 15864338]

[17] Hotamisligil GS. Inflammation and metabolic disorders. Nature 2006; 444(7121): 860-7. [http://dx.doi.org/10.1038/nature05485] [PMID: 17167474]

[18] Libby P. Inflammatory mechanisms: the molecular basis of inflammation and disease. Nutr Rev 2007; 65(12 Pt 2): S140-6. [http://dx.doi.org/10.1111/j.1753-4887.2007.tb00352.x] [PMID: 18240538]

[19] Medzhitov R. Origin and physiological roles of inflammation. Nature 2008; 454(7203): 428-35. [http://dx.doi.org/10.1038/nature07201] [PMID: 18650913]

[20] Mantovani A, Allavena P, Sica A, Balkwill F. Cancer-related inflammation. Nature 2008; 454(7203): $436-44$. [http://dx.doi.org/10.1038/nature07205] [PMID: 18650914]

[21] Nguyen XM, Lane J, Smith BR, Nguyen NT. Changes in inflammatory biomarkers across weight classes in a representative US population: a link between obesity and inflammation. J Gastrointest Surg 2009; 13(7): 1205-12.

[http://dx.doi.org/10.1007/s11605-009-0904-9] [PMID: 19415399] 
[22] Pitsavos C, Tampourlou M, Panagiotakos DB, et al. Association Between Low-Grade Systemic Inflammation and Type 2 Diabetes Mellitus Among Men and Women from the ATTICA Study. Rev Diabet Stud 2007; 4(2): 98-104. [http://dx.doi.org/10.1900/RDS.2007.4.98] [PMID: 17823694]

[23] de Waal Malefyt R, Figdor CG, Huijbens R, et al. Effects of IL-13 on phenotype, cytokine production, and cytotoxic function of human monocytes. Comparison with IL-4 and modulation by IFN-gamma or IL-10. J Immunol 1993; 151(11): 6370-81. [PMID: 7902377]

[24] Matsushita K, Yatsuya H, Tamakoshi K, et al. Inverse association between adiponectin and C-reactive protein in substantially healthy Japanese men. Atherosclerosis 2006; 188(1): 184-9.

[http://dx.doi.org/10.1016/j.atherosclerosis.2005.10.031] [PMID: 16325822]

[25] Ouchi N, Kihara S, Arita Y, et al. Novel modulator for endothelial adhesion molecules: adipocyte-derived plasma protein adiponectin. Circulation 1999; 100(25): 2473-6. [http://dx.doi.org/10.1161/01.CIR.100.25.2473] [PMID: 10604883]

[26] Chandran M, Phillips SA, Ciaraldi T, Henry RR. Adiponectin: more than just another fat cell hormone? Diabetes Care 2003; 26(8): 2442-50. [http://dx.doi.org/10.2337/diacare.26.8.2442] [PMID: 12882876]

[27] Tilg H, Moschen AR. Adipocytokines: mediators linking adipose tissue, inflammation and immunity. Nat Rev Immunol 2006 ; $6(10)$ : 772-83. [http://dx.doi.org/10.1038/nri1937] [PMID: 16998510]

[28] Fain JN. Release of interleukins and other inflammatory cytokines by human adipose tissue is enhanced in obesity and primarily due to the nonfat cells. Vitam Horm 2006; 74: 443-77. [http://dx.doi.org/10.1016/S0083-6729(06)74018-3] [PMID: 17027526]

[29] Patel SR, Zhu X, Storfer-Isser A, et al. Sleep duration and biomarkers of inflammation. Sleep 2009; 32(2): $200-4$. [PMID: 19238807]

[30] Gomez-Merino D, Drogou C, Guezennec CY, et al. Comparison of systemic cytokine responses after a long distance triathlon and a 100-km run: relationship to metabolic and inflammatory processes. Eur Cytokine Netw 2006; 17(2): 117-24. [PMID: 16840030]

[31] Neubauer O, König D, Wagner KH. Recovery after an Ironman triathlon: sustained inflammatory responses and muscular stress. Eur J Appl Physiol 2008; 104(3): 417-26.

[http://dx.doi.org/10.1007/s00421-008-0787-6] [PMID: 18548269]

[32] Nieman DC, Dumke CL, Henson DA, McAnulty SR, Gross SJ, Lind RH. Muscle damage is linked to cytokine changes following a 160-km race. Brain Behav Immun 2005; 19(5): 398-403. [http://dx.doi.org/10.1016/j.bbi.2005.03.008] [PMID: 16061149]

[33] Suzuki K, Peake J, Nosaka K, et al. Changes in markers of muscle damage, inflammation and HSP70 after an Ironman Triathlon race. Eur J Appl Physiol 2006; 98(6): 525-34. [http://dx.doi.org/10.1007/s00421-006-0296-4] [PMID: 17031693]

[34] Hamer M, Chida Y. Associations of very high C-reactive protein concentration with psychosocial and cardiovascular risk factors in an ageing population. Atherosclerosis 2009; 206(2): 599-603.

[http://dx.doi.org/10.1016/j.atherosclerosis.2009.02.032] [PMID: 19339014]

[35] Hamburg NM, McMackin CJ, Huang AL, et al. Physical inactivity rapidly induces insulin resistance and microvascular dysfunction in healthy volunteers. Arterioscler Thromb Vasc Biol 2007; 27(12): 2650-6. [http://dx.doi.org/10.1161/ATVBAHA.107.153288] [PMID: 17932315]

[36] Mora S, Lee IM, Buring JE, Ridker PM. Association of physical activity and body mass index with novel and traditional cardiovascular biomarkers in women. JAMA 2006; 295(12): 1412-9. [http://dx.doi.org/10.1001/jama.295.12.1412] [PMID: 16551713]

[37] Irwin MR, Wang M, Campomayor CO, Collado-Hidalgo A, Cole S. Sleep deprivation and activation of morning levels of cellular and genomic markers of inflammation. Arch Intern Med 2006; 166(16): 1756-62. [http://dx.doi.org/10.1001/archinte.166.16.1756] [PMID: 16983055]

[38] Irwin MR, Wang M, Ribeiro D, et al. Sleep loss activates cellular inflammatory signaling. Biol Psychiatry 2008; 64(6): 538-40. [http://dx.doi.org/10.1016/j.biopsych.2008.05.004] [PMID: 18561896]

[39] Mills PJ, von Känel R, Norman D, Natarajan L, Ziegler MG, Dimsdale JE. Inflammation and sleep in healthy individuals. Sleep 2007; 30(6): 729-35. [PMID: 17580594]

[40] Okun ML, Coussons-Read M, Hall M. Disturbed sleep is associated with increased C-reactive protein in young women. Brain Behav Immun 2009; 23(3): 351-4. [http://dx.doi.org/10.1016/j.bbi.2008.10.008] [PMID: 19007876]

[41] Taheri S, Austin D, Lin L, Nieto FJ, Young T, Mignot E. Correlates of serum C-reactive protein (CRP) - no association with sleep duration or sleep disordered breathing. Sleep 2007; 30(8): 991-6.

[PMID: 17702268] 
[42] Ahonen TM, Kautiainen HJ, Keinänen-Kiukaanniemi SM, Kumpusalo EA, Vanhala MJ. Gender difference among smoking, adiponectin, and high-sensitivity C-reactive protein. Am J Prev Med 2008; 35(6): 598-601. [http://dx.doi.org/10.1016/j.amepre.2008.09.011] [PMID: 18842390]

[43] García-Lorda P, Bulló M, Balanzà R, Salas-Salvadó J. C-reactive protein, adiposity and cardiovascular risk factors in a Mediterranean population. Int J Obes 2006; 30(3): 468-74. [http://dx.doi.org/10.1038/sj.ijo.0803182] [PMID: 16314875]

[44] Iwashima Y, Katsuya T, Ishikawa K, et al. Association of hypoadiponectinemia with smoking habit in men. Hypertension 2005; 45(6): 1094-100.

[http://dx.doi.org/10.1161/01.HYP.0000169444.05588.4c] [PMID: 15897361]

[45] O'Loughlin J, Lambert M, Karp I, et al. Association between cigarette smoking and C-reactive protein in a representative, population-based sample of adolescents. Nicotine Tob Res 2008; 10(3): 525-32. [http://dx.doi.org/10.1080/14622200801901997] [PMID: 18324572]

[46] Takefuji S, Yatsuya H, Tamakoshi K, et al. Smoking status and adiponectin in healthy Japanese men and women. Prev Med 2007; 45(6): 471-5. [http://dx.doi.org/10.1016/j.ypmed.2007.07.001] [PMID: 17689602]

[47] von Känel R, Bellingrath S, Kudielka BM. Association between burnout and circulating levels of pro- and anti-inflammatory cytokines in schoolteachers. J Psychosom Res 2008; 65(1): 51-9. [http://dx.doi.org/10.1016/j.jpsychores.2008.02.007] [PMID: 18582612]

[48] Pitsavos C, Panagiotakos DB, Papageorgiou C, Tsetsekou E, Soldatos C, Stefanadis C. Anxiety in relation to inflammation and coagulation markers, among healthy adults: the ATTICA study. Atherosclerosis 2006; 185(2): 320-6. [http://dx.doi.org/10.1016/j.atherosclerosis.2005.06.001] [PMID: 16005881]

[49] Boyle SH, Jackson WG, Suarez EC. Hostility, anger, and depression predict increases in C3 over a 10-year period. Brain Behav Immun 2007; 21(6): 816-23.

[http://dx.doi.org/10.1016/j.bbi.2007.01.008] [PMID: 17321106]

[50] Davidson KW, Schwartz JE, Kirkland SA, et al. Relation of inflammation to depression and incident coronary heart disease (from the Canadian Nova Scotia Health Survey [NSHS95] Prospective Population Study). Am J Cardiol 2009; 103(6): $755-61$. [http://dx.doi.org/10.1016/j.amjcard.2008.11.035] [PMID: 19268727]

[51] Elovainio M, Aalto AM, Kivimäki M, et al. Depression and C-reactive protein: population-based Health 2000 Study. Psychosom Med 2009; 71(4): 423-30. [http://dx.doi.org/10.1097/PSY.0b013e31819e333a] [PMID: 19297307]

[52] Empana JP, Sykes DH, Luc G, et al. Contributions of depressive mood and circulating inflammatory markers to coronary heart disease in healthy European men: the Prospective Epidemiological Study of Myocardial Infarction (PRIME). Circulation 2005; 111(18): $2299-305$. [http://dx.doi.org/10.1161/01.CIR.0000164203.54111.AE] [PMID: 15867179]

[53] Gimeno D, Kivimäki M, Brunner EJ, et al. Associations of C-reactive protein and interleukin-6 with cognitive symptoms of depression: 12year follow-up of the Whitehall II study. Psychol Med 2009; 39(3): 413-23. [http://dx.doi.org/10.1017/S0033291708003723] [PMID: 18533059]

[54] Hung YJ, Hsieh CH, Chen YJ, et al. Insulin sensitivity, proinflammatory markers and adiponectin in young males with different subtypes of depressive disorder. Clin Endocrinol (Oxf) 2007; 67(5): 784-9. [http://dx.doi.org/10.1111/j.1365-2265.2007.02963.x] [PMID: 17697007]

[55] Ladwig KH, Marten-Mittag B, Löwel H, Döring A, Koenig W. C-reactive protein, depressed mood, and the prediction of coronary heart disease in initially healthy men: results from the MONICA-KORA Augsburg Cohort Study 1984-1998. Eur Heart J 2005; 26(23): 2537-42. [http://dx.doi.org/10.1093/eurheartj/ehi456] [PMID: 16126719]

[56] Matthews KA, Schott LL, Bromberger J, Cyranowski J, Everson-Rose SA, Sowers MF. Associations between depressive symptoms and inflammatory/hemostatic markers in women during the menopausal transition. Psychosom Med 2007; 69(2): 124-30. [http://dx.doi.org/10.1097/01.psy.0000256574.30389.1b] [PMID: 17289830]

[57] Stewart JC, Rand KL, Muldoon MF, Kamarck TW. A prospective evaluation of the directionality of the depression-inflammation relationship. Brain Behav Immun 2009; 23(7): 936-44. [http://dx.doi.org/10.1016/j.bbi.2009.04.011] [PMID: 19416750]

[58] Surtees PG, Wainwright NW, Boekholdt SM, Luben RN, Wareham NJ, Khaw KT. Major depression, C-reactive protein, and incident ischemic heart disease in healthy men and women. Psychosom Med 2008; 70(8): 850-5. [http://dx.doi.org/10.1097/PSY.0b013e318183acd5] [PMID: 18725428]

[59] Vaccarino V, Johnson BD, Sheps DS, et al. Depression, inflammation, and incident cardiovascular disease in women with suspected coronary ischemia: the National Heart, Lung, and Blood Institute-sponsored WISE study. J Am Coll Cardiol 2007; 50(21): 2044-50. [http://dx.doi.org/10.1016/j.jacc.2007.07.069] [PMID: 18021871]

[60] van den Biggelaar AH, Gussekloo J, de Craen AJ, et al. Inflammation and interleukin-1 signaling network contribute to depressive symptoms but not cognitive decline in old age. Exp Gerontol 2007; 42(7): 693-701. [http://dx.doi.org/10.1016/j.exger.2007.01.011] [PMID: 17350781] 
[61] Whooley MA, de Jonge P, Vittinghoff E, et al. Depressive symptoms, health behaviors, and risk of cardiovascular events in patients with coronary heart disease. JAMA 2008; 300(20): 2379-88. [http://dx.doi.org/10.1001/jama.2008.711] [PMID: 19033588]

[62] Toker S, Shirom A, Shapira I, Berliner S, Melamed S. The association between burnout, depression, anxiety, and inflammation biomarkers: C-reactive protein and fibrinogen in men and women. J Occup Health Psychol 2005; 10(4): 344-62. [http://dx.doi.org/10.1037/1076-8998.10.4.344] [PMID: 16248685]

[63] Zaryski C, Smith DJ. Training principles and issues for ultra-endurance athletes. Curr Sports Med Rep 2005; 4(3): 165-70. [http://dx.doi.org/10.1097/01.CSMR.0000306201.49315.73] [PMID: 15907270]

[64] Mathur N, Pedersen BK. Exercise as a mean to control low-grade systemic inflammation. Mediators Inflamm 2008; 2008(109502): 1-6. [http://dx.doi.org/10.1155/2008/109502] [PMID: 19148295]

[65] Petersen AM, Pedersen BK. The role of IL-6 in mediating the anti-inflammatory effects of exercise. J Physiol Pharmacol 2006; 57(Suppl 10): 43-51. [PMID: 17242490]

[66] Lees SJ, Booth FW. Sedentary death syndrome. Can J Appl Physiol 2004; 29(4): 447-60. [http://dx.doi.org/10.1139/h04-029] [PMID: 15317985]

[67] Laufs U, Wassmann S, Czech T, et al. Physical inactivity increases oxidative stress, endothelial dysfunction, and atherosclerosis. Arterioscler Thromb Vasc Biol 2005; 25(4): 809-14.

[http://dx.doi.org/10.1161/01.ATV.0000158311.24443.af] [PMID: 15692095]

[68] Spriggs WH, Ed. Essentials of Polysomnography: A Training Guide and Reference for Sleep Technicians. Boston: Jones and Bartlett Publishers 2008.

[69] Cook-Mills JM, Deem TL. Active participation of endothelial cells in inflammation. J Leukoc Biol 2005; 77(4): 487-95. [http://dx.doi.org/10.1189/jlb.0904554] [PMID: 15629883]

[70] Simpson N, Dinges DF. Sleep and inflammation. Nutr Rev 2007; 65(12 Pt 2): S244-52. [http://dx.doi.org/10.1111/j.1753-4887.2007.tb00371.x] [PMID: 18240557]

[71] Natale V, Plazzi G, Martoni M. Actigraphy in the assessment of insomnia: a quantitative approach. Sleep 2009; 32(6): 767-71. [PMID: 19544753]

[72] Vgontzas AN, Bixler EO, Lin HM, Prolo P, Trakada G, Chrousos GP. IL-6 and its circadian secretion in humans. Neuroimmunomodulation 2005; 12(3): 131-40. [http://dx.doi.org/10.1159/000084844] [PMID: 15905620]

[73] Vgontzas AN, Bixler EO, Papanicolaou DA, Chrousos GP. Chronic systemic inflammation in overweight and obese adults. JAMA 2000; 283(17): 2235 .

[http://dx.doi.org/10.1001/jama.283.17.2235] [PMID: 10807374]

[74] Ludescher B, Najib A, Baar S, et al. Gender specific correlations of adrenal gland size and body fat distribution: a whole body MRI study. Horm Metab Res 2007; 39(7): 515-8. [http://dx.doi.org/10.1055/s-2007-982518] [PMID: 17611905]

[75] Kiechl S, Werner P, Egger G, et al. Active and passive smoking, chronic infections, and the risk of carotid atherosclerosis: prospective results from the Bruneck Study. Stroke 2002; 33(9): 2170-6. [http://dx.doi.org/10.1161/01.STR.0000027209.59821.98] [PMID: 12215582]

[76] Tracy RP, Psaty BM, Macy E, et al. Lifetime smoking exposure affects the association of C-reactive protein with cardiovascular disease risk factors and subclinical disease in healthy elderly subjects. Arterioscler Thromb Vasc Biol 1997; 17(10): 2167-76. [http://dx.doi.org/10.1161/01.ATV.17.10.2167] [PMID: 9351386]

[77] Edwards R. The problem of tobacco smoking. BMJ 2004; 328(7433): 217-9. [http://dx.doi.org/10.1136/bmj.328.7433.217] [PMID: 14739193]

[78] Targher G, Alberiche M, Zenere MB, Bonadonna RC, Muggeo M, Bonora E. Cigarette smoking and insulin resistance in patients with noninsulin-dependent diabetes mellitus. J Clin Endocrinol Metab 1997; 82(11): 3619-24. [http://dx.doi.org/10.1210/jcem.82.11.4351] [PMID: 9360516]

[79] Celermajer DS, Sorensen KE, Georgakopoulos D, et al. Cigarette smoking is associated with dose-related and potentially reversible impairment of endothelium-dependent dilation in healthy young adults. Circulation 1993; 88(5 Pt 1): 2149-55. [http://dx.doi.org/10.1161/01.CIR.88.5.2149] [PMID: 8222109]

[80] Zeiher AM, Schächinger V, Minners J. Long-term cigarette smoking impairs endothelium-dependent coronary arterial vasodilator function. Circulation 1995; 92(5): 1094-100.

[http://dx.doi.org/10.1161/01.CIR.92.5.1094] [PMID: 7648652]

[81] Churg A, Dai J, Tai H, Xie C, Wright JL. Tumor necrosis factor-alpha is central to acute cigarette smoke-induced inflammation and connective tissue breakdown. Am J Respir Crit Care Med 2002; 166(6): 849-54. [http://dx.doi.org/10.1164/rccm.200202-097OC] [PMID: 12231496]

[82] Fernandez-Real JM, Broch M, Vendrell J, Ricart W. Smoking, fat mass and activation of the tumor necrosis factor-alpha pathway. Int J Obes Relat Metab Disord 2003; 27(12): 1552-6. [http://dx.doi.org/10.1038/sj.ijo.0802472] [PMID: 12975637] 
[83] Szaflarski J, Burtrum D, Silverstein FS. Cerebral hypoxia-ischemia stimulates cytokine gene expression in perinatal rats. Stroke 1995; 26(6): 1093-100.

[http://dx.doi.org/10.1161/01.STR.26.6.1093] [PMID: 7762028]

[84] Helmersson J, Larsson A, Vessby B, Basu S. Active smoking and a history of smoking are associated with enhanced prostaglandin F(2alpha), interleukin-6 and F2-isoprostane formation in elderly men. Atherosclerosis 2005; 181(1): 201-7. [http://dx.doi.org/10.1016/j.atherosclerosis.2004.11.026] [PMID: 15939073]

[85] Matsuzawa Y, Funahashi T, Kihara S, Shimomura I. Adiponectin and metabolic syndrome. Arterioscler Thromb Vasc Biol 2004; 24(1): 29-33.

[http://dx.doi.org/10.1161/01.ATV.0000099786.99623.EF] [PMID: 14551151]

[86] Liu RH, Mizuta M, Matsukura S. The expression and functional role of nicotinic acetylcholine receptors in rat adipocytes. J Pharmacol Exp Ther 2004; 310(1): 52-8. [http://dx.doi.org/10.1124/jpet.103.065037] [PMID: 14993259]

[87] Soares AF, Guichardant M, Cozzone D, et al. Effects of oxidative stress on adiponectin secretion and lactate production in 3T3-L1 adipocytes. Free Radic Biol Med 2005; 38(7): 882-9. [http://dx.doi.org/10.1016/j.freeradbiomed.2004.12.010] [PMID: 15749384]

[88] Toth MJ, Tchernof A, Sites CK, Poehlman ET. Effect of menopausal status on body composition and abdominal fat distribution. Int J Obes Relat Metab Disord 2000; 24(2): 226-31.

[http://dx.doi.org/10.1038/sj.ijo.0801118] [PMID: 10702775]

[89] Nowak Ł, Adamczak M, Wiecek A. Blockade of sympathetic nervous system activity by rilmenidine increases plasma adiponectin concentration in patients with essential hypertension. Am J Hypertens 2005; 18(11): 1470-5. [http://dx.doi.org/10.1016/j.amjhyper.2005.05.026] [PMID: 16280284]

[90] Powell JT. Vascular damage from smoking: disease mechanisms at the arterial wall. Vasc Med 1998; 3(1): 21-8. [http://dx.doi.org/10.1177/1358836X9800300105] [PMID: 9666528]

[91] Fried SK, Bunkin DA, Greenberg AS. Omental and subcutaneous adipose tissues of obese subjects release interleukin-6: depot difference and regulation by glucocorticoid. J Clin Endocrinol Metab 1998; 83(3): 847-50. [http://dx.doi.org/10.1210/jcem.83.3.4660] [PMID: 9506738]

[92] Shirom A. Burnout in work organizations. In: Cooper CL, Robertson IT, Eds. International Review of Industrial and Organizational Psychology. New York: Wiley 1989; pp. 25-48.

[93] Shirom A. Job-related burnout: A review. In: Quick JC, Tetrick LE, Eds. Handbook of Occupational Health Psychology. Washington: American Psychological Association 2003; pp. 245-64. [http://dx.doi.org/10.1037/10474-012]

[94] Spielberger CD, Gorsuch RL, Lushene RE. Manual for The State-Trait Anxiety Inventory. Palo Alto: Consulting Psychologists Press 1970.

[95] Kawachi I, Colditz GA, Ascherio A, et al. Prospective study of phobic anxiety and risk of coronary heart disease in men. Circulation 1994; 89(5): 1992-7. [http://dx.doi.org/10.1161/01.CIR.89.5.1992] [PMID: 8181122]

[96] Späth-Schwalbe E, Hansen K, Schmidt F, et al. Acute effects of recombinant human interleukin-6 on endocrine and central nervous sleep functions in healthy men. J Clin Endocrinol Metab 1998; 83(5): 1573-9. [http://dx.doi.org/10.1210/jcem.83.5.4795] [PMID: 9589658]

[97] Wichers M, Maes M. The psychoneuroimmuno-pathophysiology of cytokine-induced depression in humans. Int J Neuropsychopharmacol 2002; 5(4): 375-88. [http://dx.doi.org/10.1017/S1461145702003103] [PMID: 12466036]

[98] Müller N, Schwarz MJ, Dehning S, et al. The cyclooxygenase-2 inhibitor celecoxib has therapeutic effects in major depression: results of a double-blind, randomized, placebo controlled, add-on pilot study to reboxetine. Mol Psychiatry 2006; 11(7): 680-4. [http://dx.doi.org/10.1038/sj.mp.4001805] [PMID: 16491133]

[99] Tyring S, Gottlieb A, Papp K, et al. Etanercept and clinical outcomes, fatigue, and depression in psoriasis: double-blind placebo-controlled randomised phase III trial. Lancet 2006; 367(9504): 29-35. [http://dx.doi.org/10.1016/S0140-6736(05)67763-X] [PMID: 16399150]

[100] Beck AT, Steer RA, Garbin MG. Psychometric properties of the Beck Depression Inventory: twenty-five years of evaluation. Clin Psychol Rev 1988; 8(1): 77-100. [http://dx.doi.org/10.1016/0272-7358(88)90050-5]

[101] Rifai N, Tracy RP, Ridker PM. Clinical efficacy of an automated high-sensitivity C-reactive protein assay. Clin Chem 1999; 45(12): $2136-41$. [PMID: 10585345]

[102] Sakkinen PA, Macy EM, Callas PW, et al. Analytical and biologic variability in measures of hemostasis, fibrinolysis, and inflammation: assessment and implications for epidemiology. Am J Epidemiol 1999; 149(3): 261-7. [http://dx.doi.org/10.1093/oxfordjournals.aje.a009801] [PMID: 9927222] 
[103] Sothern RB, Roitman-Johnson B, Kanabrocki EL, et al. Circadian characteristics of circulating interleukin-6 in men. J Allergy Clin Immunol 1995; 95(5 Pt 1): 1029-35.

[http://dx.doi.org/10.1016/S0091-6749(95)70104-4] [PMID: 7751499]

[104] Ladwig KH, Marten-Mittag B, Baumert J, Löwel H, Döring A. Case-finding for depressive and exhausted mood in the general population: reliability and validity of a symptom-driven diagnostic scale. Results from the prospective MONICA/KORA Augsburg Study. Ann Epidemiol 2004; 14(5): 332-8

[http://dx.doi.org/10.1016/j.annepidem.2003.09.003] [PMID: 15177272]

(C) George Vrousgos; Licensee Bentham Open.

This is an open access article licensed under the terms of the Creative Commons Attribution-Non-Commercial 4.0 International Public License (CC BY-NC 4.0) (https://creativecommons.org/licenses/by-nc/4.0/legalcode), which permits unrestricted, non-commercial use, distribution and reproduction in any medium, provided the work is properly cited. 